Ieachs in England and Wales 1979-1981. London: HMSO, 1986. (Report on health and social subjects No 29. )

2 House of Commons Social Services Committee. First report on perinatal, neonatal and infant mortality. Session 1988/89. London: HMSO, 1988

3 Working group on the confidential enquiry into stillbirths and deaths in infancy. Report of the working group set up by the chief medical officer. London: infancy. Report of the working

4 Clarke M, Clayton DG, Mason ES, MacVicar J Asion mothers' risk of cerinatal death he same or different? A 10 year review of Leices the perinatal deaths $B M 71988,297: 384-7$.

5 Cain KC, Breslow NE. Logistic regression analysis and efficient design for two stage studies. Am $\mathcal{F}$ Epidemiol 1988;128:1198-206.

6 Wigglesworth J. Monitoring perinatal mortality: a pathophysiologica approach. Lancet 1980;ii:684-6.
7 Nightingale F. Introductory notes on lying-in institutions. London: Longmans, Green, 1871.

8 Campling EA, Devlin HB, Hoile RW, Lunn JN. The repont of the National Confidential Enquiry into Perioperative Deaths 1990. London: National Confidential Enquiry into Perioperative Deaths, 1992.

9 Fink A, Yano EM, Brook RH. The condition of the literature on differences in hospital mortality. Med Care 1989;27:315-36.

10 Campbell R, MacDonald Davies I, Macfarlane A, Beral V. Home births in England and Wales, 1979: perinatal mortality according to intended place of delivery $B M 7$ 1984:289:721-4.

11 Tew M. Place of birth and perinatal mortality. $f R$ Coll Gen Pract 1985;35: $390-4$

(Accepted 7 fanuary 1993)
Department of Health, Richmond House, London SW1A 2NS

Morag Campbell Stern, senior registrar

\section{Department of}

Epidemiology and Public Health, University of Leicester, Leicester Royal Infirmary, PO Box 65, Leicester LE2 7LX

Carol Jagger, lecturer in medical statistics Michael Clarke, professor of epidemiology

Department of Psychiatry, University of Leicester Judith Anderson, honorary senior lecturer

\section{Department of}

Epidemiology and Public Health, University of Leicester

Catherine McGrother, senior lecturer

Department of Medicine for the Elderly, University of Leicester

Tim Battock, senior registrar

Social Services

Department, Leicestershire County

Council, Leicester

Cate McDonald, planning

officer, services for older people

Correspondence and requests for reprints to: Dr Jagger.

BMF 1993;306:827-30

\title{
Residential care for elderly people: a decade of change
}

\author{
Morag Campbell Stern, Carol Jagger, Michael Clarke, Judith Anderson, Catherine McGrother, \\ Tim Battock, Cate McDonald
}

Abstract

Objective-To determine the changes between 1979 and 1990 in demography and dependency levels in elderly people in residential care.

Design-Censuses of those aged 65 years and over in any type of residential care at midnight on 11 December 1979 and 27 November 1990.

Setting-Leicestershire District Health Authority (population 865133, 1991 census), coterminous with county and social services boundaries.

Main outcome measures-Age, sex, length of stay, and dependency levels (measured by activities of daily living).

Results-In 1990 (1979), 6079 (4678) elderly people were enumerated in 241 (133) establishments, a $30 \%$ increase in the numbers of elderly people in residential care and an $82 \%$ increase in the number of establishments between 1979 and 1990 . Dependency levels rose between 1979 and 1990 in all but the geriatric sector, the greatest increases being found in private residential homes where the largest percentage increase in the number of residents had occurred.

Conclusions-Dependency levels in residential care have risen substantially, particularly in the private sector, even beyond levels expected from the greater numbers of elderly people. With the impending move to community care, dependency levels are likely to rise further, and more appropriate staff training and medical input to homes will become necessary.

\section{Introduction}

Substantial changes in the provision of long term care for elderly people have taken place over the pas decade. Increased interest in using NHS geriatric beds for assessment and rehabilitation has led to increased turnover and shorter length of stay, ${ }^{1}$ with an expansion of acute beds and a decrease in the number of long stay beds. Government policy has been to close large mental hospitals and wherever possible to move to care in the community, ${ }^{2}$ with a resulting decrease in the number of psychiatric hospital beds. At the same time, local authorities have been subject to increasing financial constraints, resulting in the level of provision of accommodation by social services remaining static or even contracting slightly. ${ }^{3}$

The private residential sector, on the other hand, has expanded considerably, with greater numbers of both homes for elderly people and nursing homes. ${ }^{4}$ The reasons for this are a political philosophy of increasing private provision coupled with changes in the funding arrangements for those entering residential care, specifically the introduction of supplementary benefit payments to those unable to afford the fees at private homes. ${ }^{4}$ Entry then became based on financial rather than medical or social assessment, ${ }^{5}$ and in 1983 upper limits were set on supplementary benefit, resulting in a massive increase in the total national bill for supplementary benefits to people in private sector homesfrom $f 105 \mathrm{~m}$ in 1983 to $f 500 \mathrm{~m}$ by $1986 .{ }^{\circ}$ Concern that this uncontrolled expansion of the private sector had been siphoning off funds that might have been more cost effectively used in home based community $\mathrm{care}^{7}$ led to the government commissioning reviews of resource management and quality of care ${ }^{89}$ These formed the basis for the 1990 National Health Service and Community Care Act, the final phase of which is to be implemented in 1993. ${ }^{10}$

The first census of people over 65 in residential care in Leicestershire was undertaken in 1976, with a second in $1979 .{ }^{11-13}$ Given the changes over the previous decade, a further review of the size and distribution of the Leicestershire residential care sector was considered to be essential both to set an information baseline before the implementation of the National Health Service and Community Care Act and to document changes in the demography and levels of dependency of the residential care population. This paper presents comparisons of the residential care populations in 1979 and 1990.

\section{Methods}

The survey population comprised all those aged 65 years and over who were resident in any type of ward, hospital, home, or hostel provided by the NHS, local authority social services department, or private and voluntary agencies within Leicestershire at midnight on 27 November 1990. The time of year was chosen to be as close as possible to that of the 1979 census to ensure that seasonal mortality effects would not confound results. The census was confined to homes containing four or more residents registered (under the provision of the 1984 Registered Homes Act) with the health authority or the local authority for purely practical reasons. Homes with fewer than four residents are not, as yet, required to register with social services, and since no formal list of these homes exists, the size of this sector remains unknown.

Questionnaires were delivered to each establishment in the week before census night by members of the University of Leicester departments undertaking the survey, who explained the questionnaire to a senior staff member. The questionnaire, covering demographic details and levels of health and functioning, was completed by care staff for each person in their 
establishment on census night. The information collected, which was directly comparable with that obtained in 1979, fell into two broad sections: demographic data, including date and place of admission, date of birth, sex, and marital status; and information on functioning of residents during the previous week in activities necessary for daily living such as mobility, continence, and the ability to wash and dress and to feed.

For each resident, mobility was assessed on four levels (fully ambulant, ambulant apart from stairs, needing attendant or aid, bedfast). Washing and dressing and also feeding were classified as requiring no supervision, supervision only, or help on at least one occasion. Urinary incontinence was classified as dry requiring prompting, occasionally incontinent, and frequently incontinent, and faecal incontinence was either present or absent. A fuller description of the derivation of these questions on activities of daily living has already been provided. ${ }^{11}{ }^{12}$ As in 1979 , individual questions were combined to form a total activity of daily living score ranging from 0 to 11 , with higher scores denoting higher dependency.

\section{STATISTICAL METHODS}

The changes in specific variables (such as mobility) in the types of care between the censuses were assessed by forming cross classifications between the type of care, year of census, the variable of interest, age group, and sex. (Age and sex were included to account for the changing age and sex structures of the populations between the censuses.) The resulting tables were analysed by $\log$ linear modelling techniques using generalised linear interactive modelling. ${ }^{14}$

\section{Results}

In 1990, 6079 residents were enumerated in 241 establishments, including 21 NHS hospitals, 160 homes for elderly people ( 46 run by the social services departments, 105 private residential, and nine run by voluntary agencies), 32 private nursing homes, and four hospitals or hostels for the mentally or physically handicapped (table I). Twelve homes refused to take part and for these homes only basic information on the type of home, address, and number of beds was available. All 12 homes, spread throughout the county, were in the private sector, nine being residential homes, two nursing homes, and one run by a voluntary agency. The maximum number of residents in total in the 12 homes was 281 , the smallest home refusing to participate having six beds and the two largest 41 beds.

The response rate in the 1990 census was $95.3 \%$ for establishments and $95.6 \%$ for residents (enumeration of establishments was complete in 1979). These figures constituted an increase of $82 \%$ in the number of establishments and $30 \%$ in the number of elderly
TABLE II-Percentages (proportions) of people over age 65 in residential care in Leicestershire in 1979 and 1990 by age group

\begin{tabular}{lcc}
\hline Age group & 1979 & 1990 \\
\hline $65-74$ & $1\left(1033 / 70000^{\star}\right)$ & $1(967 / 72200 \dagger)$ \\
$75-84$ & $6\left(1962 / 34100^{\star}\right)$ & $5(2430 / 44600 \dagger)$ \\
$\geqslant 85$ & $21\left(1637 / 7700^{\star}\right)$ & $23(2679 / 11900 \dagger)$ \\
\hline Total & $4 \cdot 2(4678 \ddagger / 112500)$ & $4 \cdot 7(6079 / 128700)$ \\
\hline
\end{tabular}

$\star 1979$ population estimates from OPCS.

+1990 population estimates from Trent health mid-1989 population estimates (October 1990).

$\ddagger$ Total exceeds sum of subgroups as exact ages of 46 individuals in 1979 and three in 1990 were not recorded.

TABLE III-Total life expectancy, life expectancy in and outside of residential care, and proportion of total life expectancy spent outside residential care at specific ages

\begin{tabular}{|c|c|c|c|c|}
\hline $\begin{array}{l}\text { Age } \\
\text { (years) }\end{array}$ & $\begin{array}{l}\text { Total life } \\
\text { expectancy } \\
\text { (a) }\end{array}$ & $\begin{array}{c}\text { Life } \\
\text { expectancy } \\
\text { outside } \\
\text { residential care } \\
\text { (b) }\end{array}$ & $\begin{array}{c}\text { Life } \\
\text { expectancy in } \\
\text { residential care }\end{array}$ & $\begin{array}{c}\text { (b) }+(a) \\
(\%)\end{array}$ \\
\hline \multicolumn{5}{|l|}{ Men: } \\
\hline 65 & $14 \cdot 22$ & 13.74 & 0.48 & $96 \cdot 6$ \\
\hline 70 & $11 \cdot 20$ & $10 \cdot 69$ & 0.51 & $95 \cdot 5$ \\
\hline 75 & $8 \cdot 65$ & $8 \cdot 08$ & 0.56 & $93 \cdot 5$ \\
\hline 80 & $6 \cdot 64$ & 6.00 & 0.65 & $90 \cdot 3$ \\
\hline 85 & $5 \cdot 21$ & $4 \cdot 43$ & $0 \cdot 78$ & $85 \cdot 0$ \\
\hline 90 & $4 \cdot 38$ & 3.73 & 0.66 & $85 \cdot 0$ \\
\hline \multicolumn{5}{|c|}{ Women: } \\
\hline 65 & 18.03 & $16 \cdot 89$ & $1 \cdot 15$ & $93 \cdot 6$ \\
\hline 70 & $14 \cdot 43$ & $13 \cdot 23$ & 1.20 & 91.7 \\
\hline 75 & $11 \cdot 19$ & 9.91 & 1.28 & $88 \cdot 6$ \\
\hline 80 & 8.39 & $7 \cdot 01$ & 1.38 & $83 \cdot 5$ \\
\hline 85 & $6 \cdot 15$ & $4 \cdot 69$ & $1 \cdot 46$ & $76 \cdot 2$ \\
\hline 90 & 4.54 & $3 \cdot 46$ & $1 \cdot 08$ & $76 \cdot 2$ \\
\hline \multicolumn{5}{|l|}{ All: } \\
\hline 65 & $16 \cdot 30$ & $15 \cdot 45$ & 0.85 & $94 \cdot 8$ \\
\hline 70 & 13.03 & $12 \cdot 13$ & 0.91 & $93 \cdot 0$ \\
\hline 75 & $10 \cdot 18$ & $9 \cdot 18$ & 1.00 & $90 \cdot 2$ \\
\hline 80 & $7 \cdot 77$ & 6.65 & $1 \cdot 13$ & $84 \cdot 6$ \\
\hline 85 & $5 \cdot 88$ & $4 \cdot 61$ & $1 \cdot 27$ & $78 \cdot 4$ \\
\hline 90 & $4 \cdot 51$ & 3.53 & 0.97 & $78 \cdot 4$ \\
\hline
\end{tabular}

people resident since 1979 (table I). Full details of the 1979 census have been published..$^{1213}$

The proportion of people aged 65 years and over in residential care in Leicestershire was $4.2 \%$ in 1979 and $4.7 \%$ in 1990 , similar to the national level of around $5 \% .^{4}$ When these figures are broken down into age groups a strong increasing gradient with age is obvious (table II). Estimates of life expectancy in residential care at specific ages can be calculated by using a method proposed by Sullivan which applies the age specific and sex specific prevalences in five year bands to the 1990 population figures and death rates for England and Wales. ${ }^{15}{ }^{16}$ In 1990 men aged 65 years could expect to spend around six months of their 14.2 years of remaining life expectancy in residential care; for women of the same age this figure was $1 \cdot 1$ remaining years, an amount greater both absolutely and as a proportion of total remaining life expectancy (table III). In fact, women at all ages spent proporTABLE I-Establishments in Leicestershire surveyed, 1979 and 1990; numbers of residents aged 65 years and over; and percentage changes in residents, $1979-90$

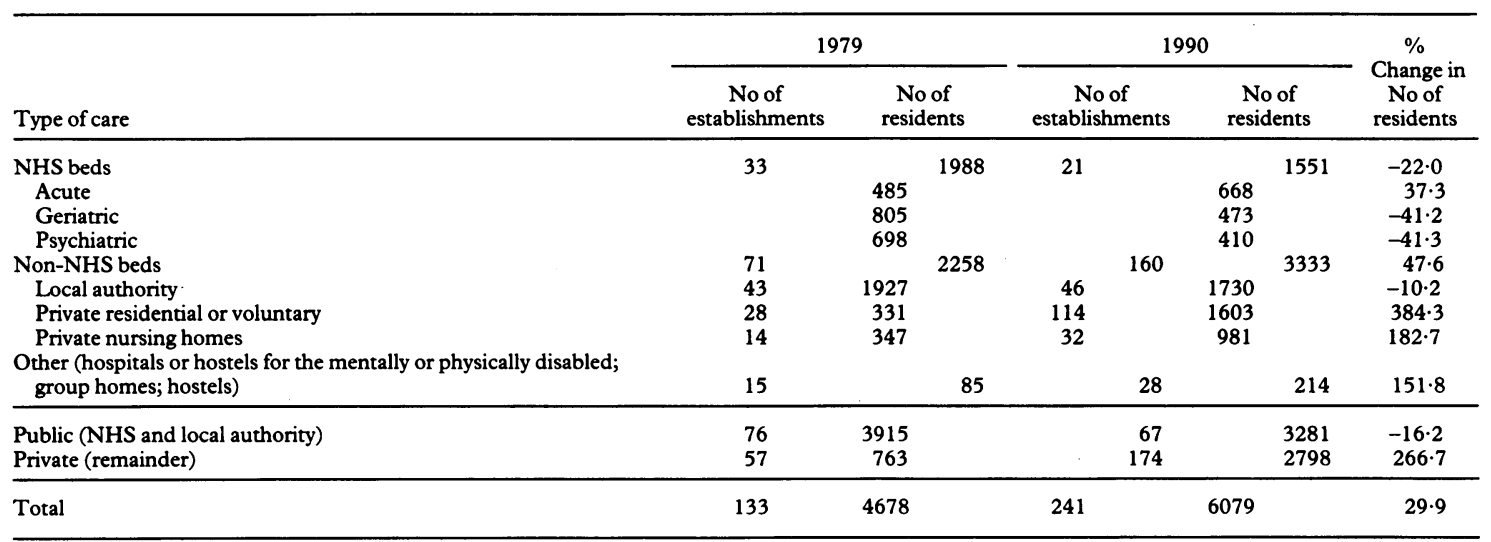


tionately more of their remaining life expectancy in residential care than men.

The major demographic changes that occurred between 1979 and 1990, in particular the increase in very elderly people ( 85 years and over), had significant effects on the age and sex structure of the majority of the care sectors (table IV). As a consequence of the changing age-sex distribution of the population over the decade between the censuses, we have grouped comparisons of other demographic and health factors by age and sex.

The total activity of daily living score was dichotomised into high dependency (score 7-11) and other. Subsequent analysis showed that in all cases there had been significant changes in the proportions with high dependency over the decade between the censuses after age and sex standardisation $\left(\chi^{2}=18 \cdot 0, \mathrm{df}=1\right.$, $\mathrm{p}<0.0001$ ), and these changes were significantly different between types of care $\left(\chi^{2}=61 \cdot 2, \mathrm{df}=6\right.$, $\mathrm{p}<0.0001$ ) (table V). Analysis of the separate components of mobility, washing and dressing, feeding, and urinary and faecal incontinence gave the same results.

TABLE IV-People over 65 in residential care in Leicestershire, 1979 and 1990, populations by sex and age group and type of care (numbers)

\begin{tabular}{|c|c|c|c|c|c|c|c|c|}
\hline \multirow[b]{2}{*}{ Type of care } & & \multicolumn{2}{|c|}{ Age 65-74 } & \multicolumn{2}{|c|}{ Age 75-84 } & \multicolumn{2}{|c|}{ Age $\geqslant 85$} & \multirow[b]{2}{*}{ Total } \\
\hline & & Men & Women & Men & Women & Men & Women & \\
\hline \multicolumn{9}{|l|}{ NHS beds: } \\
\hline Acute & 1979 & 124 & 109 & 75 & 110 & 22 & 44 & 484 \\
\hline & 1990 & 138 & 126 & 114 & 166 & 34 & 89 & 667 \\
\hline Geriatric & 1979 & 54 & 93 & 93 & 277 & 49 & 230 & 796 \\
\hline & 1990 & 40 & 39 & 72 & 144 & 35 & 143 & 473 \\
\hline Psychiatric & 1979 & 117 & 165 & 80 & 229 & 15 & 85 & 691 \\
\hline & 1990 & 45 & 70 & 77 & 118 & 23 & 77 & 410 \\
\hline \multirow{3}{*}{$\begin{array}{l}\text { Non-NHS beds: } \\
\text { Local authority }\end{array}$} & & & & & & & & \\
\hline & 1979 & 111 & 172 & 251 & 562 & 178 & 639 & 1913 \\
\hline & 1990 & 67 & 93 & 175 & 479 & 169 & 745 & 1728 \\
\hline \multirow{4}{*}{$\begin{array}{l}\text { Private residential or } \\
\text { voluntary } \\
\text { Nursing homes }\end{array}$} & 1979 & 6 & 32 & 23 & 108 & 24 & 134 & 327 \\
\hline & 1990 & 45 & 89 & 142 & 493 & 123 & 711 & 1603 \\
\hline & 1979 & 7 & 32 & 24 & 107 & 7 & 164 & 341 \\
\hline & 1990 & 46 & 71 & 99 & 294 & 70 & 401 & 981 \\
\hline \multirow[t]{2}{*}{ Other } & 1979 & 5 & 5 & 6 & 10 & 3 & 26 & 55 \\
\hline & 1990 & 46 & 52 & 15 & 42 & 12 & 47 & 214 \\
\hline \multirow{4}{*}{$\begin{array}{l}\text { Public (NHS and local } \\
\text { authority) } \\
\text { Private (remainder) }\end{array}$} & 1979 & 406 & 539 & 499 & 1178 & 264 & 998 & 3884 \\
\hline & 1990 & 290 & 328 & 438 & 907 & 261 & 1054 & 3278 \\
\hline & 1979 & 18 & 69 & 53 & 225 & 34 & 324 & 723 \\
\hline & 1990 & 137 & 212 & 256 & 829 & 205 & 1159 & 2798 \\
\hline Total & $\begin{array}{l}1979 \\
1990\end{array}$ & $\begin{array}{l}424 \\
427\end{array}$ & $\begin{array}{l}608 \\
540\end{array}$ & $\begin{array}{l}552 \\
694\end{array}$ & $\begin{array}{l}1403 \\
1736\end{array}$ & $\begin{array}{l}298 \\
466\end{array}$ & $\begin{array}{l}1322 \\
2213\end{array}$ & $\begin{array}{l}4607 \\
6076\end{array}$ \\
\hline
\end{tabular}

TABLE V-Percentages of people over 65 in Leicestershire with high dependency (total activity of daily living score 7-11) in care by sex and age group, 1979 and 1990

\begin{tabular}{|c|c|c|c|c|c|c|c|c|}
\hline \multirow[b]{2}{*}{ Type of care } & & \multicolumn{2}{|c|}{ Age 65-74 } & \multicolumn{2}{|c|}{ Age 75-84 } & \multicolumn{2}{|c|}{ Age $\geqslant 85$} & \multirow[b]{2}{*}{ Total } \\
\hline & & Men & Women & Men & Women & Men & Women & \\
\hline \multicolumn{9}{|l|}{ NHS beds: } \\
\hline \multirow[t]{2}{*}{ Acute } & 1979 & 11 & 15 & 22 & 19 & 9 & 36 & 17 \\
\hline & 1990 & 11 & 10 & 17 & 18 & 30 & 29 & 17 \\
\hline \multirow[t]{2}{*}{ Geriatric } & 1979 & 52 & 45 & 45 & 47 & 56 & 59 & 51 \\
\hline & 1990 & 38 & 30 & 46 & 42 & 50 & 48 & 44 \\
\hline \multirow[t]{2}{*}{ Psychiatric } & 1979 & 16 & 21 & 29 & 44 & * & 62 & 34 \\
\hline & 1990 & 25 & 30 & 51 & 53 & 68 & 73 & 50 \\
\hline \multicolumn{9}{|l|}{ Non-NHS beds: } \\
\hline \multirow{2}{*}{ Local authority } & 1979 & 14 & 16 & 13 & 17 & 15 & 21 & 17 \\
\hline & 1990 & 11 & 13 & 12 & 19 & 19 & 23 & 19 \\
\hline \multirow{2}{*}{$\begin{array}{l}\text { Private residential or } \\
\text { voluntary }\end{array}$} & 1979 & $\star$ & 13 & 4 & 2 & 0 & 8 & 5 \\
\hline & 1990 & 3 & 22 & 10 & 17 & 16 & 18 & 17 \\
\hline \multirow[t]{2}{*}{ Private nursing homes } & 1979 & ^ & 31 & 38 & 44 & * & 35 & 37 \\
\hline & 1990 & 63 & 57 & 56 & 51 & 49 & 50 & 52 \\
\hline \multirow[t]{2}{*}{ Other } & 1979 & * & $\star$ & ^ & * & * & 27 & 25 \\
\hline & 1990 & 8 & 7 & * & 8 & * & 24 & 13 \\
\hline \multirow{2}{*}{$\begin{array}{l}\text { Public (NHS and local } \\
\text { authority) }\end{array}$} & 1979 & 19 & 22 & 23 & 29 & 23 & 34 & 27 \\
\hline & 1990 & 17 & 17 & 26 & 26 & 29 & 30 & 26 \\
\hline \multirow[t]{2}{*}{ Private (remainder) } & 1979 & * & 22 & 21 & 22 & 6 & 23 & 22 \\
\hline & 1990 & 25 & 30 & 29 & 28 & 28 & 29 & 29 \\
\hline \multirow[t]{2}{*}{ Total } & 1979 & 18 & 2 & 23 & 28 & 21 & 31 & 26 \\
\hline & 1990 & 19 & 22 & 27 & 27 & 28 & 30 & 27 \\
\hline
\end{tabular}

${ }^{\star}$ Estimates unstable as fewer than 20 cases.

\section{Discussion}

Unbiased estimates of dependency levels in the different sectors can be achieved only by high enumeration and response rates. Despite the large increase in the private sector, which has no single administrative body to which all private homes belong, only 12 homes refused to participate in the 1990 census, rendering it most unlikely that the changes in both demography and dependency in any sector are a result of response bias. Recording error on the part of staff, either purposeful or accidental, is less easily dealt with in a study such as this. Where possible, data items were cross checked against one another and the establishments were asked to clarify the few inconsistencies that arose. What is not clear is the direction of any bias that might have occurred. Staff of private establishments in 1990 may have overestimated the actual disability of their residents, or the methods of care in these homes may lead to increased dependency. On the other hand, some staff may have underestimated dependency in order that homes did not appear understaffed. Although these biases cannot be refuted, in reality the staff completing the schedules tended to be those dealing with residents on a day to day basis, rather than home owners and managers, who might have been more concerned with the implications the results may have had for their establishment.

The changes that have occurred since 1979 in the pattern of long term care for older people in Leicestershire, above and beyond the aging of the general population, highlight some of the challenges that many local authorities face in implementing the final phase of the "Caring for People" community care reforms. Firstly, it is clear that a transfer of responsibility has taken place between the different forms of provision. The reduction in the scale of long term geriatric provision has been accompanied by an increase in the provision of residential care and nursing homes. Likewise, the decrease in the proportion of highly dependent people in NHS beds has been countered by increases in the proportions of dependent people in other sectors. Many would also argue that this process has continued into the community, with a greater proportion of people with complex care needs now remaining in the community rather than entering some form of residential care.

Several researchers report similar results in particular sectors, ${ }^{41718}$ though they have not shown the complete picture. On the other hand, not all geographical areas have yet seen the same changes. Our findings contrast with those of Campbell in South Belfast and Stott et al in Glasgow, ${ }^{19}{ }^{20}$ since geriatricians in both Scotland and Northern Ireland have continued to provide long term care and the growth in the private sector began somewhat later than in England.

Although considerable variations remain in the levels of dependency (as measured by activity of daily living scores) of people accommodated in different forms of provision, this distinction seems to have narrowed since 1979. This suggests that there is now a greater degree of overlap in the characteristics of people accommodated in different forms of care. This blurring of the boundaries may be of little consequence to users of the service, but it does have implications for the type of care they receive and which agency remains financially responsible for arranging that care. Though the number of people over the age of 65 is predicted not to increase over the next 10 years and to rise slowly thereafter, ${ }^{21}$ the profile of this group will change considerably. Later cohorts of elderly people may be fitter, ${ }^{22}$ although medical science is unlikely to alleviate the major impact of chronic degenerative diseases. Any further increases in dependency levels in local authority and private residential homes will have 
implications for staff training and morale as well as for more frequent medical assessment. ${ }^{18}$

Finally, both health authorities and local authorities are firmly committed to a policy of supporting older people in their own homes for as long as possible. Surprisingly, the results of this third census in Leicestershire show that the proportion of older people in some form of residential care increased little over the past decade. The greater absolute numbers of elderly people have been absorbed by the growing private sector despite a simultaneous collapse of long term provision in the NHS, and this has been widely attributed to the impact of the central government funding system for private residential care. This remains the situation that social service departments will inherit in April 1993, when social services assume responsibility for private care. Managing this situation while at the same time implementing the organisational, funding, and cultural changes that are required must be regarded as one of the foremost challenges facing local authorities.

We thank all the nursing and care staff working in NHS hospitals and homes, local authority homes, and in the private and voluntary care sectors. We were given invaluable help by the directors of nursing services in the NHS hospital units: Miss B Wallam, Mrs P Lucas, Mrs W Elsdon, Mr C Aggett, Mr M Halpin, Mrs K Lockett, and Mrs C Parsons. The cooperation of the Care Homes Associations was vital to the completeness of the study and we are grateful, in particular, to Mrs M Newham (East Midlands Combined Association of Residential Establishments), Mr M R Wilson (Leicestershire Association of Residential Care Homes), Mr T Banbury (Registered Nursing Home Association), and Mr N McKinlay (Leicestershire Health Authority). We are indebted to all the registrars, senior registrars, lecturers, consultants, and research assistants of the university and NHS departments of psychiatry, medicine for the elderly, epidemiology and public health, and public health medicine who gave their time to deliver, collect, and check questionnaires. Mr N Raymond and Mrs C Douglas provided essential support for data collection and analysis. Thanks also go to Mrs S King, Mrs P Payne, and $\mathrm{Mr} \mathrm{J}$ Woods of the department of epidemiology and public health.

Financial support for the study was provided by Leicestershire Health Authority.

1 Wilkin D, Mashiah T, Jolley DJ. Changes in behavioural characteristics of elderly populations of local authority homes and long-stay hospital wards, elderly populations of local

2 Department of Health and Social Security. Better services for the mentally ill. London: HMSO, 1975.

3 Grundy E, Arie T. Falling rate of provision of residential care for the elderly. BMF 1982;284:799-802.

4 Laing and Buisson. Care of elderly people. London: Laing and Buisson Publications, 1988.

5 Lowy S, Briggs R. Boom in private rest homes in Southampton: impact on the elderly in residential care. BMF 1988;296:541-3.

6 Day P, Klein R. Quality of institutional care and the elderly: policy issues and options. $B M$ I 1987;294:384-7.

7 Godber C. Private rest homes: answers needed. BMY 1984;288:1473-4.

8 Griffiths R. Community care: agenda for action. London: HMSO, 1988.

A positive choice. London: HMSO, 1988 . Wagner committee report)

10 Secreturies of State for Health, Social Security, $W_{\text {ales, }}$ and Scotlond. Caring for pertectial Security, Wales, and Scotland. Caring for

people: commo, 1989.

Clarke M, Hughes AO, Dodd KJ, Palmer RL, Brandon S, Holden AM, et al. The elderly in residential care: patterns of disability. Health Trends 1979;11:17-20

12 Donaldson LJ, Clarke M, Palmer RL. Institutional care for the elderly: the impact and implications of the ageing population. Health Trends 1983;15: 58-61.

13 Donaldson LJ. Characteristics of elderly people misplaced in hospitals and homes. Public Health 1983;97:257-63.

14 Baker RJ, Nelder JA. The GLIM 3.77 user and reference guides. Oxford: Numerical Algorithms Group, 1985.

15 Sullivan DF. A single index of mortality and morbidity. Health Services and Mental Health Administration. Health report 1971;86:347-54.

16 Office of Population Censuses and Surveys. Monality statistics. London: HMSO, 1990. (Series DHI, No 24.)

17 Grundy E. Community care for the elderly 1976-84. BMF 1987;294:626-9.

18 Gosney M, Tallis R, Edmond E. The burden of chronic illness in local authority residential homes for the elderly. Health Trends 1991;22:153-7.

19 Stott DJ, Dutton M, Williams BO, MacDonald J. Functional capacity and mental status of elderly people in long term care in West Glasgow. Health
mott DJ, Dutton M, Williams BO, MacDonald J. Functional capacity and Bulletin 1990;48:17-24.

20 Campbell H, Crawford V, Stout RW. The impact of private residential and hospital care of elderly people in South Belfast. Age Ageing 1990;19:318-24.

21 Office of Population Censuses and Surveys. National population projection 1989-based. London: HMSO, 1991. (Series PP2 No 17.)

22 Jagger $C$, Clarke $M$, Clarke SJ. Getting older-feeling younger: the changing health profile of the elderly. Int $\mathcal{F}$ Epidemiol 1991;20:234-8.

(Accepted 2 March 1993)

\begin{abstract}
Department of
Neuropsychiatry, School qf

Medicine Keio

University, Shinanomachi,

Shinjuku-ku, Tokyo 160,

Japan

Aya Nishizono-Maher,

senior registrar in psychiatry
\end{abstract}

Division of Haematology,

Keio University

Yoshihiro Masuda,

consultant

Department of

Haematology, Tokyo

Komagome Hospital,

Bunkyo-ku, Tokyo 113

Hisashi Sakamaki, consultant

Third Division of

Internal Medicine,

National Defence Medical

College, Saitama-ken 359,

Japan

Takashige Kuraki, registrar

Hiroaki Mizukami,

consultant

\section{Tokyo Institute of}

Psychiatry, Kamikitazawa,

Setagaya-ku, Tokyo

Kuninao Minakawa,

associate director

Correspondence to:

Dr Nishizono-Maher.

BMF 1993;306:830-1

\section{Leukaemia linked to eating disorders}

\author{
Aya Nishizono-Maher, Hisashil Sakamaki, \\ Hiroaki Mizukami, Takashige_Kuraki, \\ Kuninao-Minakawa, Yoshihiro Masuda
}

Eating disorders are common in industrialised countries. Because of treatment such as intravenous hyperalimentation many anorectic patients now survive instead of dying from emaciation. Some patients, however, have chronic anorectic symptoms and remain in a prolonged state of malnutrition. Bulimic symptoms may emerge later, increasing the person's physiological and nutritional imbalance. The haematological and immunological aspects of anorexia nervosa have been widely investigated, ${ }^{1-5}$ but to our knowledge a possible connection between eating disorders and leukaemia has not been described. We report on three patients who developed myelocytic leukaemia after protracted eating disorders. None had a history of exposure to excessive radiation or to other potential sources of leukaemia.

\section{Case reports}

Case 1-A 20 year old woman, whose body weight had fluctuated from $50 \mathrm{~kg}$ in the summer to $60 \mathrm{~kg}$ in the winter since she was 16 , had developed the habit of vomiting when frustrated. When 23 years old she presented to a psychiatrist with a weight of $40 \mathrm{~kg}$ (height $158 \mathrm{~cm}$ ). Suspecting hypokalaemia, the psychiatrist performed a blood test, which showed leukaemia. Detailed haematological investigations showed the presence of Philadelphia chromosome, low neutrophil alkaline phosphatase activity, and a high vitamin B-12 concentration. Chronic myelocytic leukaemia was diagnosed and was initially well controlled by chemotherapy. After 10 months, however, a blastic crisis developed, and despite intensive chemotherapy the patient died seven months later.

Case 2-A 22 year old woman began dieting and developed symptoms of anorexia. She presented to a psychiatrist with a weight of $37 \mathrm{~kg}$ (height $162 \mathrm{~cm}$ ), amenorrhoea, mysophobic symptoms, and compulsive hand washing. The results of a blood test were normal. Psychotherapy was started, but though this gradually alleviated her obsessive symptoms, she remained anorectic. At age 27 she developed purpura over her arms and legs, and acute promyelocytic leukaemia (French-American British classification, M3 type) was diagnosed. She was also found to have disseminated intravascular coagulation. Her leukaemia went into remission after chemotherapy, and bone marrow transplantation was planned.

Case 3-A woman who had been overweight since childhood reduced her weight from $75 \mathrm{~kg}$ to $48 \mathrm{~kg}$ (height $156 \mathrm{~cm}$ ) by dieting between the ages of 15 and 17. She also developed the habit of vomiting and misusing laxatives. She was amenorrhoeic for about one year and received hormonal treatment from a gynaecologist for several months. From the age of 18 her weight remained stable between $48 \mathrm{~kg}$ and $50 \mathrm{~kg}$ owing to frequent bouts of binging and vomiting. She 